\title{
PROFIL KESEHATAN SPIRITUAL TENAGA PENDIDIK AKPER PEMKAB LUMAJANG
}

\section{(PROFILE OF SPIRITUAL HEALTH OF EDUCATORS LUMAJANG NURSING ACADEMY)}

\author{
Laili Nur Azizah \\ Prodi D3 Keperawatan Universitas Jember Kampus Lumajang \\ Jl Brigjen Katamso Lumajang Kode Post 67311 \\ e-mail: lailinurazizah3@gmail.com
}

\begin{abstract}
ABSTRAK
Pendidikan keperawatan merupakan bagian dari pendidikan kesehatan sebagaimana halnya pendidikan kedokteran, kesehatan masyarakat, farmasi, kedokteran gigi dan lain-lain. Sebagaimana halnya bahwa pendidik adalah juga sebagai pemimpin, maka terdapat beberapa cara agar seseorang bisa memiliki karakter Powerful Leader. Diantaranya adalah membangun seorang powerful leader berbasis spiritualitas, atau dengan kata lain, seorang pemimpin yang tangguh dan berhati nurani. Tujuan penelitian ini adalah menjelaskan profil kesehatan spiritual tenaga pendidik Akper Pemkab Lumajang. Jenis penelitian yang dipilih adalah deskriptif. Sedangkan rancangan penelitian yang digunakan adalah cross sectional. Populasi dalam penelitian ini adalah seluruh tenaga pendidik Akper pemkab Lumajang, dengan tekhnik samping menggunakan total sampling. Sampel yang digunakan adalah 21 orang Tempat penelitian di Akper Pemkab Lumajang dengan waktu yang dibutuhkan untuk pengambilan data adalah selama 2 minggu. Instrument yang digunakan adalah menggunakan kuesioner Indonesia Spiritual Health Assessment (ISHA) dari C-Net (centre for neuroscience health and Spirituality) UIN Sunan Kalijaga Yogyakarta. Hasil penelitian menunjukkan bahwa pada responden, 11 orang mempunyai pengalaman spiritual excellent, 10 orang mempunyai pengalaman spiritual optimal, 14 orang mempunyai emosi positif excellent, 7 orang mempunyai emosi positif optimal, 17 orang mempunyai makna hidup excellent, 4 orang mempunyai makna hidup optimal, 13 orang mempunyai ritual excellent, 8 orang mempunyai ritual optimal. Kesimpulan hasil penelitian menunjukkan sebagian besar responden menunjukkan mempunyai pengalaman spiritual, emosi positif, makna hidup dan ritual berada pada kategori excellent. Hasil penelitian menunjukkan bahwa kesehatan spiritual tenaga pendidik pada Akper Pemkab Lumajang sebagian besar excellent.

Kata kunci: Kesehatan Spiritual, tenaga pendidik
\end{abstract}

\section{ABSTRACT}

Nursing education is part of health education as well as medical education, public health, pharmacy, dentistry and others. Just as the educator is also a leader, there are several ways that a person can have a Powerful Leader character. Among them is building a powerful leader based on spirituality, or in other words, a leader who is tough and conscientious. The purpose of this study is to explain the profile of spiritual health of educators Lumajang Nursing Academy. The research type chosen is descriptive. While the research design used is cross sectional. Population in this research is all educator Lumajang Nursing Academy, using total sampling. The sample used is 21 people The research site in Lumajang Nursing Academy with the time required for data collection is for 2 weeks. The instrument used is the Indonesian Spiritual Health Assessment (ISHA) questionnaire from C-NET (center for neuroscience health and Spirituality) UIN Sunan Kalijaga Yogyakarta. The result is 11 
people have experience of spiritual excellent, 10 people have optimal spiritual experience, 14 people have excellent positive emotion, 7 people have optimal positive emotion, 17 people have the meaning of life is excellent, 4 people have optimal life meaning, 13 people have excellent ritual, 8 people have optimal ritual. The conclusion of the research shows that most of the respondents show that they have spiritual experience, positive emotion, life meaning and ritual are in the excellent category. The results showed that the spiritual health of educators at Lumajang Nursing Academy mostly excellent.

Keywords: Spiritual Health, Educators

\section{PENDAHULUAN}

\section{Pendidikan}

merupakan bagian dari pendidikan kesehatan sebagaimana halnya pendidikan kedokteran, kesehatan masyarakat, farmasi, kedokteran gigi dan lain-lain. Perkembangan pendidikan keperawatan sudah dimulai sejak lokakarya tahun 1983 dengan dibenahi sistem pendidikan melalui peningkatan sistem pendidikan ke jenjang pendidikan tinggi sebagai syarat pendidikan professional. Pada proses transformasi perilaku pendidikan keperawatan mampu merubah peserta didik untuk mencapai professional perawat dengan melaksanakan asuhan keperawatan dengan benar dan baik. Sebagai institusi pendidikan tinggi keperawatan harus mampu membina dan menumbuhkan sikap dan tingkah laku professional sesuai dengan kemampuan profesi, memberi landasan ilmu pengetahuan yang kokoh baik kelompok ilmu keperawatan atau kelompok ilmu dasar atau penunjang asuhan keperawatan, membina ketrampilan professional yang mencakup ketrampilan intelektual, tekhnikal dan interpersonal serta membina landasan etik keperawatan sebagai dasar dalam kehidupan keprofesian (Aziz Alimul H, 2002).

Disamping itu, pihak-pihak yang mengelola pendidikan tinggi keperawatan dan pihak-pihak yang berkepentingan atau berhubungan dengan pendidikan tinggi keperawatan agar benar-benar memahami arti dan makna pendidikan keperawatan sebagai pendidikan profesi dan melaksanakan pendidikan keperawatan secara keseluruhan. Perkembangan keperawatan Indonesia di masa depan sangat tergantung pada keberhasilan dalam membina pendidikan tinggi keperawatan (Nursalam dan Ferry E, 2012).

Dalam pengembangan standar kompetensi perawat, dibutuhkan 25 karakter diantaranya adalah berperilaku etis. Dalam penguasaan soft skill berprilaku etis, pendidik diharapkan dapat memotivasi (berbagi pengalaman, studi kasus, kisah sukses), memberi tugas yang bersifat tantangan, memberi teladan, serta memberi penghargaan atas prestasi mahasiswa (Nursalam dan Ferry E, 2012).

Pendidik ialah orang yang memikul pertanggungjawaban untuk mendidik. Pengertian pendidik ini meliputi: orang dewasa, orang tua, guru, pemimpin masyarakat, dan pemimpin agama. Secara umum dikatakan bahwa setiap orang dewasa dalam masyarakat dapat menjadi pendidik, sebab pendidikan merupakan suatu perbuatan sosial, perbuatan fundamental yang menyangkut keutuhan perkembangan pribadi anak didik menuju pribadi dewasa susila (Hasbullah, 2009). Sebagaimana halnya bahwa pendidik adalah juga sebagai pemimpin, maka terdapat beberapa cara agar seseorang bisa memiliki karakter Powerful Leader. Diantaranya adalah membangun seorang powerful leader berbasis spiritualitas, atau dengan kata lain, seorang pemimpin yang tangguh dan berhati nurani. Cirinya adalah mereka sangat sadar untuk mempelajari diri mereka sendiri. Seorang powerful leader senantiasa menyadari bahwa fisik, emosi dan spiritual adalah modal dasar yang sangat penting untuk menjalankan kegiatan. Intelektual Quotient (IQ) penting dalam kehidupan agar bisa memanfaatkan tekhnologi demi efisiensi dan efektifitas. Peran Emotional Quotient (EQ) adalah 
untuk membangun hubungan antar manusia yang baik dan efektif. Sedangkan Spiritual Quotient (SQ) mengajarkan nilai-nilai kebenaran. Spiritualisme mampu menghasilkan lima hal, yaitu: integritas atau kejujuran, energy atau semangat, inspirasi atau ide dan inisiatif, wisdom atau kebijaksanaan, serta keberanian dalam mengambil keputusan dalam kehidupan sebagai manusia (Agustian, Ary Ginanjar, 2003).

Kesehatan spiritual merupakan keharmonisan antara individu dengan orang lain, alam dan kehidupan yang tertinggi. Keharmonisan ini dicapai ketika seseorang menemukan keseimbangan antara nilai, tujuan dan sistem mereka dengan hubungan mereka di dalam diri dan dengan orang lain. Setiap individu mempunyai tiga kebutuhan yang harus dipenuhi untuk mencapai sehat spiritual, yaitu kebutuhan akan arti dan tujuan hidup, kebutuhan untuk mencintai dan berhubungan, dan kebutuhan untuk mendapatkan pengampunan (Hungelmann et al, 1985, dalam Potter dan Perry, 2005).

Pembangunan karakter dijadikan sebagai motto utama kementerian Pendidikan Nasional sejak setahun lalu, begitu juga dengan pembinaan mental pada pelbagai institusi, tetapi fakta menunjukkan bahwa sebagian besar anak bangsa belum betul-betul mengembangkan dengan baik seluruh potensi yang dimilikinya, terutama potensi spiritual (UIN Sunan Kalijaga, 2012). Realita yang terjadi adalah proses pendidikan banyak menekankan pada segi kognitif saja, apalagi hanya nilai-nilai ujian yang menjadi standart kelulusan, sehingga peserta didik tidak berkembang menjadi manusia yang utuh. Akibat selanjutnya, akan terjadi beragam tindakan yang tidak baik seperti yang akhir-akhir ini terjadi : perkelahian, penghilangan etnis, ketidakadilan, kesenjangan ekonomi, korupsi, ketidakjujuran dan sebagainya (Salamah, 2011). Dari pemberitaan media elektronik banyak menampilkan beritaberita tentang VCD porno mahasiswa, aksi tawuran dan perkelahian, narkoba, alkohol, seks bebas, demo anarkis sampai dengan tindak kriminalitas. Menurut laporan yang dicetak oleh Kompas Cyber Media pada tanggal 5 Februari 2001, dari 2 juta pecandu narkoba dan obat-obat berbahaya, 90\% diantaranya adalah generasi muda, termasuk diantaranya 25.000 adalah mahasiswa (Sinulingga, R, 2008).

Sehingga belum tampak adanya suatu kesehatan spiritual komunitas (spiritual community health) yang menjadi kekuatan pendorong bagi perubahan bangsa yang mestinya dimiliki oleh masyarakat Indonesia, melalui titik tumpunya pada kesehatan spiritual individual. Ini artinya, masalah potensi spiritual manusia belum menjadi perhatian penting dibandingkan dengan pengembangan potensi fisik dan mental (UIN Sunan Kalijaga, 2012).

Sebagai satu-satunya perguruan tinggi kesehatan milik Pemerintah Kabupaten Lumajang, Akademi Keperawatan Pemkab Lumajang mengembangkan ilmu pengetahuan tidak saja bersumber dari metode-metode ilmiah kesehatan, tetapi juga menekankan spiritualitas dalam kehidupan kampus sehari-hari. Akper Pemkab Lumajang menyelenggarakan kajian Islam di selasela kegiatan pembelajaran dalam setiap minggunya. Tetapi hal tersebut tidaklah cukup untuk mencetak perawat yang tangguh secara mental dan spiritual. Untuk mewujudkan harapan ini, maka dibutuhkan tenaga pendidik yang mempunyai semangat dan tingkat spiritual yang tinggi pula. Dari fenomena tersebut, maka penulis tertarik untuk melakukan penelitian tentang Profil Kesehatan Spiritual Tenaga pendidik Pada Akper Pemkab Lumajang Tahun 2016.

Tujuan penelitian ini adalah menjelaskan profil kesehatan spiritual tenaga pendidik Akper Pemkab Lumajang meliputi pengalaman spiritual, emosi positif, makna hidup, dan ritual. 


\section{METODE}

Jenis penelitian yang dipilih adalah deskriptif. Sedangkan rancangan penelitian yang digunakan adalah cross sectional. Populasi dalam penelitian ini adalah seluruh tenaga pendidik Akper pemkab Lumajang, dengan tekhnik samping menggunakan total sampling. Sampel yang digunakan adalah 21 orang dengan karakteristik responden tercatat aktif sebagai tenaga pendidik Akper Pemkab Lumajang, memiliki NIDN, serta bersedia menjadi responden penelitian.

Tempat penelitian di Akper Pemkab Lumajang dengan waktu yang dibutuhkan untuk pengambilan data adalah selama 2 minggu.

Instrument yang digunakan untuk mengukur kesehatan spiritual adalah menggunakan kuesioner Indonesia Spiritual Health Assessment (ISHA) dari C-Net (centre for neuroscience health and Spirituality) UIN Sunan Kalijaga Yogyakarta. ISHA terdiri dari total 117 item terdiri dari 90item spiritualitas dan 27 item dominansi otak. Hasil tes berupa profil kesehatan excellent, optimal dan improvement.

Prosedur pengambilan data dengan cara peneliti mendatangi responsen berdasarkan keriteria inklusi. Setelah mendapatkan persetujuan responden, maka dilakukan pengisian kuesioner ISHA pada. Kuesioner bisa dibawa pulang dan responden diminta untuk mengisi kuesioner. Lembar jawab kuesioner yang telah terisi diserahkan kepada tim C-NET UIN Sunan Kalijaga Yogyakarta untuk dilakukan proses skoring, dan hasil skoring ISHA dikirimkan kembali oleh CNET UIN Sunan Kalijaga Yogyakarta kepada peneliti untuk dilakukan analisis.

Analisa data dilakukan dengan cara pengkodean data, pemindahan data ke computer dan kemudian hasil pengolahan data ditampilkan dalam bentuk numeric dalam table distribusi frekuensi.

\section{HASIL}

Karakteristik sampel yang meliputi umur, jenis kelamin, dan riwayat pendidikan.

Tabel 1. Distribusi umur responden

\begin{tabular}{lll}
\hline Umur (tahun) & $\mathbf{n}$ & $\mathbf{\%}$ \\
\hline $18-40$ & 15 & 71.4 \\
$40-60$ & 6 & 28.6 \\
$>60$ & 0 & 0 \\
Total & 21 & 100 \\
\hline
\end{tabular}

Tabel di atas menunjukkan bahwa sebagian besar responden berada pada usia dewasa menengah/madya (40-60 tahun ).

Tabel 2. Distribusi jenis kelamin responden

\begin{tabular}{lll}
\hline Jenis Kelamin & n & \% \\
\hline Laki-laki & 8 & 39.1 \\
Perempuan & 13 & 61.9 \\
Total & 21 & 100 \\
\hline
\end{tabular}

Tabel di atas menunjukkan bahwa sebagian besar responden berjenis kelamin perempuan.

\section{Kesehatan Spiritual}

Dari hasil skoring kuesioner, didapatkan peta kesehatan spiritual sebagai berikut:

Tabel 3. Peta Kesehatan Spiritual berdasarkan Pengalaman Spiritual, Emosi Positif, Makna Hidup, dan Ritual pada responden

\begin{tabular}{|c|c|c|c|c|c|c|c|c|}
\hline \multirow{2}{*}{$\begin{array}{l}\text { Keseha } \\
\text { tan } \\
\text { Spiritu } \\
\text { al }\end{array}$} & \multicolumn{2}{|c|}{$\begin{array}{l}\text { Pengala } \\
\text { man } \\
\text { Spiritual }\end{array}$} & \multicolumn{2}{|c|}{$\begin{array}{l}\text { Emosi } \\
\text { Positif }\end{array}$} & \multicolumn{2}{|c|}{$\begin{array}{l}\text { Makna } \\
\text { Hidup }\end{array}$} & \multicolumn{2}{|c|}{ Ritual } \\
\hline & $\mathrm{f}$ & $\%$ & $\mathrm{f}$ & $\%$ & $\mathrm{f}$ & $\%$ & $\mathrm{f}$ & $\%$ \\
\hline $\begin{array}{l}\text { Excelle } \\
\mathrm{nt}\end{array}$ & 11 & 52.4 & 14 & 66.7 & 17 & 80.9 & 13 & 61.9 \\
\hline Optima & 10 & 47.6 & 7 & 33.3 & 4 & 19.1 & 8 & 39.1 \\
\hline $\begin{array}{l}\text { Improv } \\
\text { ement }\end{array}$ & 0 & 0 & 0 & 0 & 0 & 0 & 0 & 0 \\
\hline Jumlah & 21 & 100 & 21 & 100 & 21 & 100 & 21 & 100 \\
\hline
\end{tabular}


Tabel di atas menunjukkan bahwa pada responden, 11 orang mempunyai pengalaman spiritual excellent, 10 orang mempunyai pengalaman spiritual optimal, 14 orang mempunyai emosi positif excellent, 7 orang mempunyai emosi positif optimal, 17 orang mempunyai makna hidup excellent, 4 orang mempunyai makna hidup optimal, 13 orang mempunyai ritual excellent, 8 orang mempunyai ritual optimal.

\section{PEMBAHASAN}

\section{Kesehatan Spiritual}

Hasil penelitian menunjukkan bahwa kesehatan spiritual tenaga pendidik pada Akper Pemkab Lumajang sebagian besar excellent. Artinya kelompok subyek yang diperiksa, secara umum, memiliki ciri-ciri spiritualitas yang diinginkan kebanyakan orang yang ingin menjadi orang baik. Dalam kaitannya dengan fungsi otak, kelompok subyek menunjukkan fungsi dari 5 sistem otak yang berada pada rata-rata (Average) hingga di atas rata-rata (Optimal). Hal ini berarti kelompok subyek memiliki otak yang berfungsi dengan baik. Kelompok subyek menunjukkan keseimbangan antara kegiatan ritual dan spiritualitas.

pribadi $\begin{array}{ccr}\text { Spiritualitas adalah pandangan } \\ \text { dan }\end{array}$ mengekspresikan rasa keterkaitan ke dimensi transcendental atau untuk sesuatu yang lebih besar dari diri (Rees, 1987, dalam Asy'arie et al, 2012). Spiritualitas merupakan suatu kecenderungan untuk membuat makna hidup melalui hubungan intrapersonal, interpersonal dan transpersonal dalam mengatasi berbagai masalah kehidupan (Yusuf, 2017).

Kesehatan Spiritual atau kesejahteraan adalah "rasa keharmonisan saling kedekatan antara diri dengan orang lain, alam dan dengan kehidupan yang tertinggi" (Hungelmann et al, 1985, dalam Potter \& Perry, 2005). Rasa keharmonisan ini dicapai ketika seseorang menemukan keseimbangan antara nilai, tujuan, dan sistem keyakinan mereka dengan hubungan mereka di dalam diri mereka sendiri dan dengan orang lain. Ketidakseimbangan spiritual (Spirituality Disequilibrium) adalah sebuah kekacauan jiwa yang terjadi ketika kepercayaan yang dipegang teguh tergoncang hebat. Kekacauan ini seringkali muncul ketika penyakit yang mengancam hidup berhasil didiagnosis (Taylor, 2002, dalam Young, 2007). Indikator terpenuhinya kebutuhan spiritual adalah adanya rasa keharmonisan, saling kedekatan antara diri sendiri, orang lain, alam dan hubungan dengan yang Maha Kuasa (Yusuf, 2017).

Kesehatan spiritual adalah kondisi yang dalam pandangan sufistik disebut sebagai terbebasnya jiwa dari berbagai penyakit ruhaniah, seperti syirk (polytheist), kufr (atheist), nifaq atau munafik (hypocrite), dan fusuq (melanggar hukum). Kondisi spiritual yang sehat terlihat dari hadirnya ikhlas (ridha dan senang menerima pengaturan Illahi), tauhid (meng-Esa-kan Allah), tawakal (berserah diri sepenuhnya kepada Allah) (Hendrawan, S., 2010).

Kegiatan spiritual dalam otak manusia menurut Newberg dan D'Aquili dikutip oleh Pasiak 2012 melibatkan sejumlah komponen otak yang disebut operator kognitif yang menghasilkan pengalaman spiritual yang dapat diamati, yang terdiri dari: 1) pre frontal cortex, 2) area asosiasi, 3) system limbic, dan 4) system syaraf otonom (Yusuf, 2017).

Kesehatan spiritual tenaga pendidik pada Akper Pemkab Lumajang berada dalam kategori excellent, hal ini dapat dipengaruhi oleh kesibukan kegiatan spiritualitas tiap personal dalam kesehariannya. Usia responden yang berada dalam rentang 18-40 tahun dimana pada masa usia ini, seseorang sudah mengalami masa-masa pertentangan batin, ajakan/seruan dan sugesti, faktor emosi dan kemauan. Masa ini ditandai dengan adanya perubahan mental (Daradjat, Z, 1996). 


\section{Otak dalam melaksanakan} tugasnya sebagai kesatuan fungsional sangat berperan dalam hal ini. Terutama adalah nukleus kaudatus, bersama dengan hipokampus dalam lobus temporalis ternyata berfungsi dalam perilaku yang disebut refleks orientasi. Yakni suatu perilaku yang semula tidak terbiasa, tetapi berangsur-angsur menjadi terbiasa (Markam, 2010). Perilaku manusia seharihari sebagian juga berdasarkan pada pembentukan refleks terkondisi. Kegiatan sehari-hari kelompok responden bisa dikaitkan dengan refleks terkondisi ini, dimana responden harus bangun pagi, shalat subuh, mengikuti kajian agama (di TV atau radio atau membaca buku agama), berangkat bekerja, serta mengikuti kajian Islam di kampus (sekali dalam seminggu). Rutinitas dan ritual juga penting bagi pembelajaran yang optimal, karena rutinitas dan ritual dapat menyeimbangkan kekacauan dan ketidakpastian (Jensen, 2008).

Hal ini menguatkan teori bahwa adanya kegiatan keagamaan dapat selalu mengingatkan keberadaan dirinya dengan Tuhan, dan selalu mendekatkan diri kepada Penciptanya (Hidayat, 2006). Agama juga berkontribusi pada rasa perpaduan dan pengalaman hidup seperti yang diharapkan, dan semuanya dihubungan dengan kesehatan fisik dan mental yang lebih baik (Antonovsky, 1987, dalam Hussain D, 2010).

Faktor lain yang mungkin bisa mempengaruhi adalah pengalaman hidup sebelumnya. Seperti yang diungkapkan oleh Taylor, et al (1997) dan Craven \& Hirnle (1996) dalam Hamid (2000) bahwa pengalaman hidup baik yang positif maupun yang negatif dapat mempengaruhi spiritual seseorang dan sebaliknya juga dipengaruhi oleh bagaimana seseorang mengartikan secara spiritual pengalaman tersebut. Peristiwa dalam kehidupan seseorang dianggap suatu cobaan yang diberikan Tuhan kepada manusia menguji imannya. Hal ini ditunjang pula dengan kondisi rentang usia responden yang homogen yaitu dalam tahap dewasa muda. Pada tahap ini individu menjalani proses perkembangannya dengan melanjutkan pencarian identitas spiritual, memikirkan untuk memilih nilai dan kepercayaan mereka yang dipelajari saat kanak-kanak dan berusaha melaksanakan sistem kepercayaan mereka sendiri.

\section{Pengalaman Spiritual}

Hasil penelitian menunjukkan bahwa pengalaman sebagian besar dari responden mempunyai pengalaman spiritual excellent.

Pengalaman spiritual adalah manifestasi spiritual dalam hubungan intrapersonal, dimana seseorang mengalami suatu pengalaman spesifik dan unik berupa penyatuan dengan Zat Kudus dalam pelbagai tingkatannya, bermula dari suatu pengalaman estetik-inderawi ke pengalaman penyatuan yang lebih hakiki. Pengalaman ini dapat membuat seseorang lebur dan hilang dari dirinya sendiri, menyatu dengan alam sekitarnya, dan merasakan adanya kehadiran Tuhan dalam setiap peristiwa dan entitas. Dimensi pengalaman spiritual ditunjukkan dengan merasakan dekat dan bersahabat dengan alam semesta, menemukan Tuhan dibalik semua peristiwa, merasakan kehadiran Tuhan dalam keseharian, merasakan teguran Tuhan ketika melakukan kesalahan, merasakan kesan istimewa pada semua peristiwa dekat dan bersahabat dengan alam semesta, serta mengalami perasaan menyatu dengan Tuhan (Pasiak, 2012).

Kata kunci dalam pencapaian pengalaman spiritual adalah estetika (pengalaman indrawi biasa yang bersifat estetis), takjub (pengalaman indrawi yang sensasional atau di luar kelaziman), dan penyatuan (pengalaman non indrawi) (Yusuf, 2017).

Cortex Pre Frontalis sangat berperan dalam memperoleh pengalaman spiritual dan pencapaian makna hidup. Cortex Pre Frontal yang sehat umumnya dikaitkan dengan keadaan sadar dimana 
kemampuan berpikir mendominasi setiap tindakan (Pasiak, 2012). Hal ini dibuktikan dari hasil skoring kuesioner bahwa separuh dari dua kelompok responden menunjukkan dominansi otak cortex pre frontalis yang optimal (fungsi diatas ratarata), serta sisa responden menunjukkan dominansi otak cortex pre frontalis yang average (fungsi rata-rata).

\section{Emosi Positif}

Hasil penelitian menunjukkan bahwa sebagian besar responden mempunyai emosi positif excellent.

Emosi positif merupakan manifestasi spiritualitas dalam hubungan intrapersonal, dimana seseorang memahami dinamika kehidupan dan persoalan dalam konteks syukur, sabar dan ikhlas. Dalam manifestasi ini pikiran sadar menjadi pengendali setiap ekspresi. Dengan ini, seseorang memiliki nilai-nilai kehidupan yang didasari oleh kemampuan berpikir yang tepat (Pasiak, 2012). Kata kunci pencapaian emosi positif adalah dengan syukur, atas segala sesuatu yang sudah diberikan oleh Tuhan tanpa melalui usaha sendiri. Syukur jika diberi keberhasilan setelah melakukan usaha adalah syukur yang lebih rendah bnilainya dibandingkan dengan bersyukur atas sesuatu yang diberikan tanpa adanya usaha sama sekali). Sabar, menbuat segala sesuatu yang pahit dan tidak nyaman berada dibawah control diri dan tidak sekedar menahan diri. Dan ikhlas, melepaskan sesuatu secara sadar tanpa ada penyesalan (Yusuf, 2017).

Sistim Limbik berperan dalam ekspresi emosi positif. Sistim Limbik yang sehat umumnya dikaitkan dengan emosi yang sehat. Sistim Limbik yang sehat terjadi jika sistim limbik bekerja sama secara dinamis dengan cortex pre frontalis. Sedangkan gyrus cingulatus berperan penting sebagai fasilitator hubungan sistim limbik dan cortex pre frontalis. Gyrus cingulatus yang sehat dikaitkan dengan emosi yang terkelola dengan baik. Emosi menggerakkan atensi, menciptakan makna, dan memiliki jalur memorinya sendiri (Joseph LeDoux dalam Jensen, 2008). Disinilah sistim limbik terlibat dalam pengaturan kondisi emosional. Ketika sistim limbik kurang aktif, kondisi pikiran umumnya positif dan lebih berharap. Ketika bagian ini terlalu aktif, pikiran negatiflah yang mengambil alih. Emosi di sistim limbik merupakan penyaring yang menentukan bagaimana emosi/perasaan kita dalam menterjemahkan semua peristiwa yang terjadi dalam sehari (Asy'arie, 2012). Hal ini dibuktikan dengan hasil skoring kuesioner menunjukkan bahwa separuh responden menunjukkan dominansi otak sistim limbik yang optimal (fungsi diatas ratarata), serta sisa responden menunjukkan dominansi otak sistim limbik yang average (fungsi rata-rata). Sedangkan pada fungsi gyrus cingulatus, sebagian besar dua kelompok responden menunjukkan fungsi average (fungsi rata-rata), dan hanya sebagian kecil saja yang mempunyai fungsi optimal (fungsi diatas rata-rata).

Lamsudin dalam Asy'arie (2012) mengungkapkan bahwa dari hasil penelitian membuktikan bahwa ukuran sistim limbik pada wanita rata-rata lebih besar dibandingkan lelaki. Karena itu, maka perempuan mudah tersentuh dan secara umum lebih mampu mengungkapkan perasaannya daripada lelaki. Mereka lebih mampu membentuk ikatan dan terhubung dengan orang lain. Sistem limbik yang lebih besar membuat perempuan lebih rentan terhadap depresi, terutama saat terjadi perubahan hormon yang signifikan, seperti awal pubertas, sebelum masa haid, setelah melahirkan dan saat menopause. Teori ini menguatkan hasil penelitian bahwa sebagian besar responden adalah mempunyai jenis kelamin perempuan.

Emosi adalah aspek integral dari sistem pengoperasian neural. Emosi mempercepat kemampuan berfikir dengan memberikan respon fisik langsung kepada keadaan di sekeliling kita. Emosi dibangkitkan dari jalur yang 
diotomatisasikan secara biologis. Keenam emosi ini adalah senang, takut, terkejut/heran, jijik, marah dan sedih. Emosi adalah katalis yang mempengaruhi konversi pikiran ke dalam hal-hal fisik dalam tubuh. Ia mendistribusikan molekulmolekul peptida ke seluruh tubuh seperti sel-sel darah putih. Emosi memicu suasana hati, perilaku dan pada akhirnya kehidupan kita (Jensen, 2008).

Pengaruh emosi terhadap perilaku kita sangatlah besar. Oleh karena itu ia memberikan kepada kita laporan "langsung" setiap saat pada respons tubuh, mereka menerima status prioritas. Jaringan-jaringan penting yang memproses emosi menghubungkan sistem limbik, korteks pre frontal, dan barangkali yang terpenting adalah menghubungkan wilayah-wilayah otak yang memetakan dan mengintegrasikan sinyal-sinyal dari tubuh (Jensen, 2008).

Indikator emosi positif ditunjukkan dengan senang terhadap kebahagiaan orang lain, menikmati dengan kesadaran bahwa segala sesuatu diciptakan atas tujuan tertentu/mengambil hikmah, bersikap optimis akan pertolongan Tuhan, bisa berdamai dengan keadaan sesulit separah apapun, mampu mengendalikan diri, serta bahagia bila melakukan kebaikan (Yusuf, 2017).

\section{Makna Hidup}

Hasil penelitian menunjukkan bahwa sebagian besar dari responden mempunyai makna hidup excellent.

Makna hidup adalah manifestasi spiritualits berupa penghayatan intrapersonal yang bersifat unik, ditunjukkan dalam hubungan social (interpersonal) yang bermanfaat, menginspirasi dan mewariskan sesuatu yang bernilai bagi kehidupan manusia. Kata kunci dalam pencapaian makna hidup adalah inspiring (menumbuhkan keinginan meneladani dari orang lain) dan legacy (mewariskan sesuatu yang bernilai tinggi bagi kehidupan). Indikator makna hidup adalah menolong dengan spontan, memegang teguh janji, memaafkan diri dan orang lain, berperilaku jujur, menjadi teladan bagi orang lain, serta engutamakan keselarasan dan kebersamaan (Yusuf, 2017).

Cortex pre frontalis berperan utama dalam pencapaian makna hidup. Hal ini dibuktikan dari hasil skoring kuesioner bahwa separuh dari dua kelompok responden menunjukkan dominansi otak cortex pre frontalis yang optimal (fungsi diatas rata-rata), serta sisa responden menunjukkan dominansi otak cortex pre frontalis yang average (fungsi rata-rata). Cortex pre frontal adalah semacam central executive organizer, yang memegang kendali dalam eksekusi, pengambilan keputusan dan menempatkan nilai-nilai dalam setiap tindakan. Salah satu hasil dari kemampuan cortex pre frontal ini adalah makna hidup manusia. Keunikan manusia, keunikan cortex pre frontal dan spiritualitas, membuat makna hidup itu menjadi sangat penting. Ini menjadi tiang penyanggah utama dalam spiritualitas manusia. Seseorang yang mengalami kerusakan pada cortex pre frontal akan mengalami gangguan dalam makna hidup (Pasiak, 2012).

\section{Ritual}

Hasil penelitian menunjukkan bahwa sebagian besar dari responden mempunyai ritual excellent.

$$
\text { Ritual adalah manifestasi }
$$

spiritualitas berupa tindakan terstruktur, sistematis, berulang, melibatkan aspek motorik-kognisi dan afeksi, yang dilakukan menurut suatu tatacara tertentu baik secara individual maupun komunal. Kata kunci dalam pencapaian ritual adalah kebutuhan (ritual yang didorong oleh kebutuhan, bukan oleh sebab-sebab lain), dan rasa kehilangan sesuatu (jika tidak melaksanakannya). Bentuk ritual antara lain melakukan sembahayang, memanjatkan doa, mengunjungi tempat ibadah, sedekah, dan terlibat aktif dalam komunitas keagamaan. Indikator ritual ditunjukkan dengan merasakan 
ketergantungan/ membutuhkan Tuhan, (Pasiak, 2012).

Ritual mengaktifkan banyak komponen syaraf yang berujung pada hadirnya suasana psikologis yang memungkinkan terjadinya hubungan penyatuan dengan Tuhan. Penyatuan itu tidak berhenti sebagai akhir dari peristiwa spiritual, tetapi mengejawantah dalam kehidupan social. Dengan cara ini, spiritualitas memiliki makna social dan tidak semata-mata bernilai subyektif bagi individu (Pasiak, 2012).

Ganglia basalis mempunyai peran utama dalam kegiatan ritual. Ritual selalu melibatkan emosi, gerakan motorik dan pikiran sadar. Ganglia basalis yang sehat dikaitkan dengan pelaksanaan ritual yang sadar. Bukan sebagai kegiatan rutin belaka. Terdapat hubungan antara ganglia basalis, sistim limbik dan otak kecil. Sedangkan lobus temporalis berperan penting dalam penggunaan bahasa spesifik dalam kegiatan ritual. Doa yang diucapkan dengan bahasa-bahasa tertentu, atau ritualritual spesifik dengan ucapan-ucapan tertentu dikaitkan dengan fungsi lobus temporalis ini.

Hal ini dibuktikan dari hasil skoring kuesioner bahwa sebagian kecil responden menunjukkan dominansi otak ganglia basalis yang optimal (fungsi diatas rata-rata), serta sebagian besar menunjukkan dominansi otak sistim limbik yang average (fungsi rata-rata). Pada sisa responden, sebagian kecil responden menunjukkan dominansi otak ganglia basalis yang optimal (fungsi diatas rata-rata) dan sebagian besar menunjukkan dominansi otak ganglia basalis yang average (fungsi rata-rata). Sedangkan pada fungsi lobus temporalis, separuh dari responden menunjukkan fungsi average (fungsi rata-rata), dan separuh sisanya mempunyai fungsi optimal (fungsi diatas rata-rata).

\section{KESIMPULAN}

Kesimpulan hasil penelitian menunjukkan sebagian besar responden menunjukkan mempunyai pengalaman spiritual, emosi positif, makna hidup dan ritual berada pada kategori excellent. Hasil penelitian menunjukkan bahwa kesehatan spiritual tenaga pendidik pada Akper Pemkab Lumajang sebagian besar excellent.

Artinya kelompok subyek yang diperiksa, secara umum, memiliki ciri-ciri spiritualitas yang diinginkan kebanyakan orang yang ingin menjadi orang baik. Dalam kaitannya dengan fungsi otak, kelompok subyek menunjukkan fungsi dari 5 sistem otak yang berada pada ratarata (Average) hingga di atas rata-rata (Optimal).

Hal ini berarti kelompok subyek memiliki otak yang berfungsi dengan baik. Kelompok subyek menunjukkan keseimbangan antara kegiatan ritual dan spiritualitas.

\section{SARAN}

Saran Bagi ilmu kesehatan dan keperawatan adalah kesehatan spiritual yang optimal, dapat memperbaiki hubungan intrapersonal, interpersonal, lingkungan dan alam serta terhadap sang Pencipta Alam. Sehingga menjadi profesi yang handal tidak hanya dalam kognitif maupun skill, tetapi juga afeksi yang optimal. Untuk mewujudkan hal tersebut, dibutuhkan komunikasi yang baik.

Perawat khususnya, perlu meningkatkan ketrampilan komunikasi terapeutik baik di klinik maupun di komunitas, terutama dalam hubungan intrapersonal maupun hubungan terhadap Tuhan Sang Pencipta Alam, sehingga tercipta hubungan interpersonal yang baik khususnya kepada pasien.

Sedangkan saran bagi ilmu pendidikan adalah profesi guru dan dosen adalah profesi yang dituntut untuk bisa menjadi role model sehingga dapat dijadikan tauladan bagi peserta didik/ mahasiswa. Guru/ dosen yang memiliki kesehatan spiritual yang excellent dapat menjadikan dirinya sebagai "pencetak" 
kader bangsa dan generasi muda yang handal, tangguh secara moral dan spiritual.

\section{KEPUSTAKAAN}

Agustian, Ary Ginanjar, 2009, Rahasia Sukses Membangkitkan ESQ Power, Jakarta; Arga Publishing

Asy'arie et al, 2012, Tuhan Empirik dan Kesehatan Spiritual, Editor Taufiq Pasiak, Centre for Neuroscience, Health and Spirituality (C-NET), UIN Sunan Kalijaga Yogyakarta.

Atkinson, R.L, tt, Pengantar Psikologi, Edisi Kesebelas, Jilid 2, Batam: Interaksara

Aziz Alimul Hidayat, 2002, Pengantar Pendidikan Keperawatan, Jakarta; CV Agung Seto

Blais et al, 2006, Praktik Keperawatan Profesional, Konsep \& Perspektif, Edisi 4, Jakarta: EGC

Brignall, M., 2001, The Perception Process. Wisc-Online. Diakses tanggal 22 Februari 2016.

Cahyadi, H, et al, 2004, Peranan Heat Shock Protein Pada Patogenesis Penyakit Infeksi dan Penyakit Autoimmun, JKM, Volume 3, Nomor 2.

Efendi, A, 2008, Peran Strategis Lembaga Pendidikan Berbasis Islam di Indonesia, el Tarbawi, Jurnal Pendidikan Islam, no 1 , vol 1 , 2008, diambil dari www.journal.uii.ac.id, diakses tanggal 22 Februari 2016

Haber, J,. 1987, Comprehensive Psychiatric Nursing, 3 rd, New York: Mc Graw-Hill Book Company.

Haningsih, S. 2008, Peran Strategis Pesantren, Madrasah dan Sekolah Islam di Indonesia, el-Tabrawi, Jurnal Pendidikan Islam, no 1 vol I, 2008, diambil dari http://journal.uii.ac.id/index.php/JP I/article/viewfile/186/175, diakses tanggal 16 Februari 2016
Hamid, A, 2000, Buku Ajar Aspek Spiritual dalam Keperawatan, Jakarta: Widya Medika.

Hasanah, A, 2010, Pendidikan Modern, Yogyakarta: Diva Press.

Hasbullah, 2009, Dasar-Dasar Ilmu Pendidikan, Edisi Revisi 8, Jakarta; Rajawali Pers

Hawari, D, 2008, Integrasi Agama Dalam Pelayanan Medik, Jakarta: Balai Penerbit FKUI

Hendrawan, S., 2010, Spiritual Management, Jakarta: Mizan Publika.

Hidayat, A.A. 2009. Pengantar Kebutuhan Dasar Manusia: Aplikasi Konsep dan Proses Keperawatan, Buku 1, Jakarta: Salemba Medika.

Hussain, D., 2010, How Religion/Spirituality Effect Health?- Reflectius on Some Possible Mechanisms, International Journal of Exixtensial Psychology $\&$ Psychotherapy, vol 3 number 1

Ibrahim, S. 2010, Kondisi Pendidikan Tinggi Islam, bersumber dari http://edukasi.kompasiana.com/201 0/02/06/kondisi_pendidikan_tinggi islam/ diakses tanggal 16 Februari 2016

King and Koenig, 2009, Conseptualising Spirituality for Medical Research and Health Service Provision, BMC Health Services Research, Volume: 9, Publiser: BioMed Central, pages 116, bersumber dari www.discovery.ucl.ac.uk, diakses tanggal 12 Februari 2016

Kozier, Erb., 2004, Fundamental of Nursing: Concepts, Process and Practice, Seventh Edition, New Jersey: Pearson Education Inc.

Nursalam Dan Ferry E, 2012, Pendidikan Dalam Keperawatan, Jakarta; Salemba Medika.

O'Brien, M.E, 2010, Spirituality in Nursing, Jones and Barlett Learning, bersumber dari http://books.google.co.id, diakses tanggal 12 Februari 2016 
dalam Asuhan Keperawatan, Jakarta: Mitra Wacana Media

Potter \& Perry, 2005, Buku Ajar Fundamental Keperawatan; Konsep, Proses dan Praktik, Edisi 4 Volume 1, Jakarta: Penerbit EGC

Putra, ST, 2011, Psikoneuroimunologi Kedokteran, Edisi 2, Surabaya: Airlangga University Press.

Salamah, H, 2011, Pendidikan Multi Kultural: Upaya Keberagaman Inklusif di Sekolah, Thesis S2, IAIN Sunan Ampel, Surabaya

Sinulingga, R, 2008. Pendidikan Agama pada Perguruan Tinggi dalam Menghadapi Masalah Etis dan Moral di Era Global dan Tekhnik Informasi, Pidato Pengukuhan Guru Besar Universitas Sumatera Utara, 15 November 2008, diambil dari

http://www.usu.ac.id/id/files/pidato /ppgb/2008/ppgb_2008_risnawati.p df diakses tanggal 16 Februari 2016

Suprayogo, I., 2010, Minat Masyarakat atas Pendidikan Islam Meningkat, Republika.co.id, 29 April 2010, diakses tanggal 6 Maret 2016, http://www.republika.co.id/berita/b reakingnews/nasional/10/04/29/113 354-minat-masyarakat-ataspendidikan-islam-meningkat.

UIN Sunan Kalijaga, 2012. UIN Sunan Kalijaga Luncurkan Pusat Kesehatan Spiritual, diambil dari http://www.uinsuka.ac.id/berita/dberita/525, diakses 16 Februari 2016

UU Sisdiknas Tahun 2003. Diambil dari http://www.dikti.net/file/sisdiknas. pdf. diakses tanggal 22 Februari 2016.

Wikipedia,2012,Universitas_Universitas_I slam_Negeri_Maulana_Malik_Ibra him_Malang.webarchivexml, www.Wikipedia.com, diakses 23 Januari 2016

Yusuf, Ah, dkk, 2017, Kebutuhan Spiritual: Konsep dan Aplikasi 